\title{
Some aspects of the reproductive biology of three exotic cichlid species that colonize the Victoria reservoir, a deep upland reservoir in Sri Lanka
}

\author{
S. NATHANAEL and E.I.L. SILVA* \\ Institute of Fundamental Studies, Hantana Road, Kandy, Sri Lanka
}

*Corresponding author (E-mail: sil@ifs.ac.lk)

\begin{abstract}
Cichlids form the mainstay of the fishery of the Victoria reservoir, which is the largest and deepest hydropower reservoir constructed under the accelerated Mahaweli programme. Since there is a significant variation in the relative abundance of the three species of cichlids that colonize this reservoir, namely Oreochromis niloticus, $O$. mossambicus and Tilapia rendalli, this investigation was carried out to determine whether there are any marked differences in their reproductive biology, which favours successful colonization of one species over the others.

The reproductive biology of the three species was analyzed using standard techniques by which the mean size at maturity, fecundity, sex ratio, monthly fluctuations in maturity stages and correlations of gonadosomatic indices with rainfall were obtained. All three cichlid species are year-round breeders having around three major spawning peaks. Among the three species $O$. niloticus has the highest male dominance, the latest maturation and the best correlation between fecundity and body size, which appear to be the characters favouring its establishment in the reservoir. The higher female to male sex ratio in $O$. mossambicus in the commercial catches indicates that one of the reasons for the gradual decline of this species may be the elimination of females which are smaller in size than the males, and hence could be more susceptible to small meshed gill nets which are frequently used in this reservoir. The presence of larger heavily yolked eggs, lower fecundity and the mouth brooding habit of $O$. mossambicus and $O$. niloticus make them better adapted for survival in the reservoir than $T$. rendalli. $T$. rendalli has the lowest potential for colonizing this reservoir. The survival of this species is ensured by having a high fecundity, a 1:1 sex ratio with prolonged association between breeding pairs, and an early maturation of both sexes. The results indicate that the differences in reproductive biology play an important role in the colonization success of the three cichlid species in this reservoir.
\end{abstract}




\section{Introduction}

Victoria is the largest and deepest hydropower reservoir constructed under the accelerated Mahaweli Programme. The reservoir has a wellestablished commercial fishery comprising exotic and indigenous fish species. Cichlids constitute the mainstay of this fishery. However, the relative abundance of the three cichlid species (Oreochromis mossambicus, $O$. niloticus, and Tilapia rendalli) that colonize the reservoir differs markedly from each other (Nathanael \& Silva, 1996a).

Except for a few studies on the reproductive biology of $O$. mossambicus, O. niloticus, O. mossambicus $X$ O. niloticus hybrids (De Silva \& Chandrasoma, 1980; De Silva, 1986; Amarasinghe \& De Silva 1996) and $T$. rendalli (Chandrasoma \& De Silva, 1981) in shallow dry zone reservoirs, there is no information available on the reproductive biology of cichlids in deep upland reservoirs of Sri Lanka. As such, the main objective of this investigation is to comparatively analyze some aspects of reproductive biology, viz., abundance of fry, fecundity, gonadosomatic index, sex ratio, mean size at maturity etc., of the three exotic cichlid species found in the Victoria reservoir in order to identify whether there are any marked differences which favour the successful colonization of one species over the other two.

\section{Materials and Methods}

A fry survey was conducted for a period of one year from March 1992 to February 1993, sampling the littoral zone of the reservoir bimonthly at two randomly selected locations. On each sampling day, five hauls were made by dragging a fine meshed net within a 10-minute period.

Around thirty specimens of each of the three cichlid species were collected at monthly intervals from fish landing sites for a period of one year from January to December 1990. They were transported to the laboratory and the total and standard lengths were measured to the nearest millimeter. Their weights were also recorded to the nearest milligram. The fish were then dissected, sexed and their gonad weights were recorded. The gonadosomatic index (GSI) taken as the ratio between the gonad weight and body weight was calculated separately for each individual. The mean of each monthly sample was designated as the monthly GSI.

The gonads were separated into six stages more or less similar to those described by Chandrasoma (1980) to determine the seasonal fluctuation in gonad maturity. The mean size at maturity of each species, i.e., the length at which $50 \%$ of the population reaches maturity, was estimated by determining the $\%$ of mature individuals of stage III and above in each $1 \mathrm{~cm}$ length group as described by Chandrasoma (1980). 


\section{Reproductive biology of cichlids}

Ovaries in the mature stage were weighed to the nearest milligram, split longitudinally and preserved in Gilson's fluid. Periodic vigorous shaking of the jars containing the ovaries assisted in penetration of the preservative and in separating the eggs. Fecundity of 30 ovaries from each of the three species was estimated using an Imhof's sedimentation cone. The eggs within the cone were aerated to ensure uniform distribution, and five sub samples of $10 \mathrm{ml}$ each were drawn out. The number of eggs in this volume was counted and the total number of eggs in the bulk sample was estimated. The relationships between fecundity and total length and total weight were also determined. Rainfall data at the dam site of the Victoria Reservoir was obtained from Head-works of the Mahaweli Authority of Sri Lanka.

\section{Results}

Abundance of fry: Figure 1 shows the abundance of cichlid fry in relation to the annual rainfall pattern and water level fluctuation in the reservoir. The first peak coincided with the peak southwest monsoonal rains (JuneJuly). The highest peak coincided with the tail end of the northeast monsoons (December-January).

Mean size at maturity: Table 1 gives the mean total length at maturity of the three cichlid species studied. In all three species females appear to mature earlier than the males. In $T$. rendalli both sexes mature at smaller lengths than the other two species. The male $O$. niloticus showed $50 \%$ maturity at mean length of $25.8 \mathrm{~cm}$ and it was $22.9 \mathrm{~cm}$ and $21.3 \mathrm{~cm}$ in the case of $O$. mossambicus and $T$. rendalli respectively.

Fecundity: There was a marked variation in the fecundity of the three cichlid species. Both $O$. mossambicus and $O$. niloticus had a much lower fecundity and produced larger sized heavily yolked eggs compared to $T$. rendalli. In the case of $O$. mossambicus, the fecundity of a few mature females in the 8 to $10 \mathrm{~cm}$ size range obtained from cast net catches during the drought season was also included in Table 2.

The relationships between fecundity and total length of all three species were curvilinear whereas those between fecundity and body weight were linear (Table 2). In all three species the relationship between fecundity and body weight was more significant than those between fecundity and body length (Table 2). Of the three species, the most significant relationship between fecundity and body size (weight) was obtained for $O$. niloticus while the least significant relationship was obtained for $T$. rendalli. 


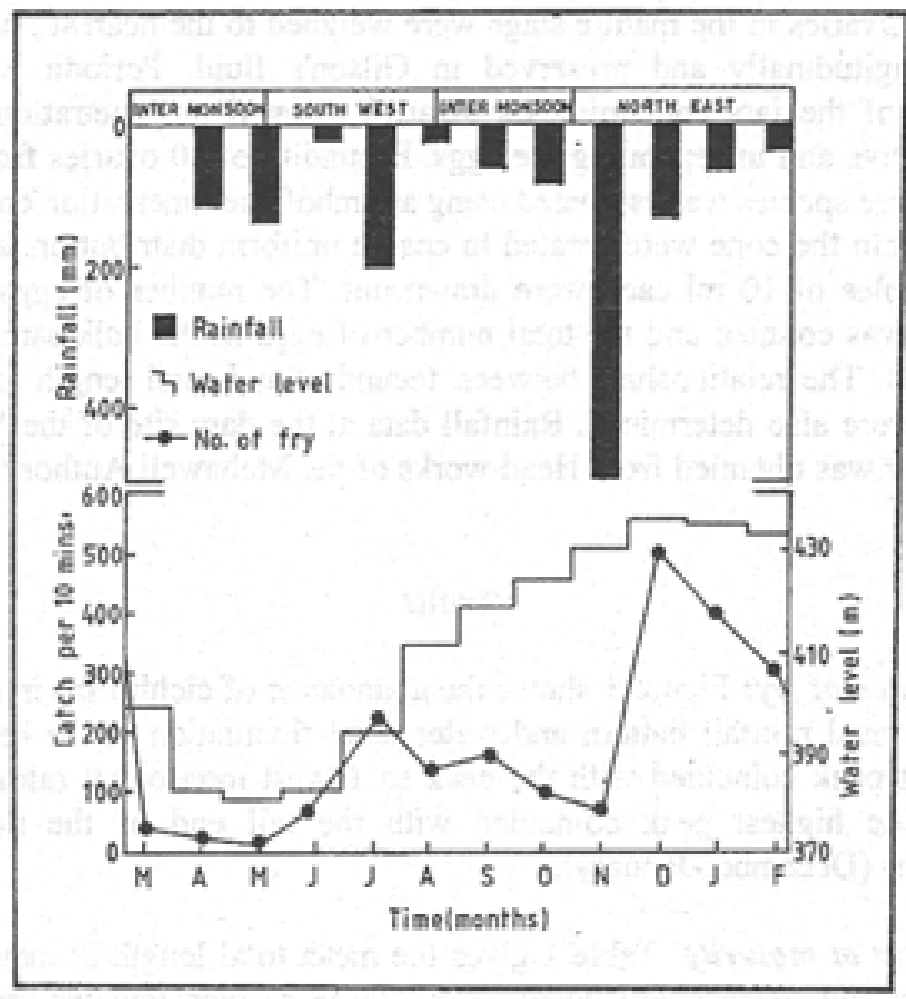

Figure 1. Fluctuation in the availability of cichlid fry in relation to the annual rainfall and water level.

Sex ratio: The sex ratios of the three cichlid species studied are given in Table 3. The results of the Chi square test with Yates correction (Neave \& Worthington 1992) revealed that there was a significant deviation from the expected 1:1 ratio in $O$. mossambicus $\left(\chi^{2}=19.67, \mathrm{p}<0.05\right)$ and $O$. niloticus $\left(\chi^{2}=22.05, p<0.05\right)$. In $T$. rendalli, however, $\left(\chi^{2}=4.70, p>0.05\right)$ deviation from the expected 1:1 sex ratio was not significant. The 1:1 sex ratio in $T$. rendalli may be due to the prolonged monogamous association of breeding pairs during substrate spawning. In all three species however, the sex ratio fluctuated with size. Males were predominant in the larger size classes whereas females were predominant in the lower size classes. It was also observed that large meshed gill nets target mostly $O$. niloticus males (which are the largest individuals among the cichlids) while small meshed gillnet catches contain high proportions of small sized $O$. mossambicus females. 
Reproductive biology of cichlids

Table 1. Mean size at maturity for males and females of the three different cichlid species.

\begin{tabular}{lcc}
\hline Species & Males $(\mathrm{cm})$ & Females $(\mathrm{cm})$ \\
\hline O. mossambicus & 22.9 & 19.2 \\
O. niloticus & 25.8 & 22.6 \\
T. rendalli & 21.3 & 18.0 \\
\hline
\end{tabular}

Table 2. Fecundity and the relationships of fecundity to body length $(\mathrm{L})$ and body weight $(\mathrm{W})$ in the three cichlid species. $\left(\mathrm{r}=\right.$ correlation coefficient; ${ }^{* *}$ $\left.\mathrm{p}<0.001 ;{ }^{*} \mathrm{p}<0.01\right)$.

\begin{tabular}{llll}
\hline & $O$. mossambicus & O. niloticus & T. rendalli \\
\hline Fecundity & $108-713$ & $570-1574$ & $1,020-7,495$ \\
Total length range $(\mathrm{cm})$ & $18-27.5$ & $20.1-28.5$ & $18.2-25.2$ \\
Relationship with total & $0.68 \mathrm{~L}^{1.50}$ & $0.36 \mathrm{~L}^{3.15}$ & $0.19 \mathrm{~L}^{1.17}$ \\
length & $(\mathrm{r}=0.69)^{* *}$ & $(\mathrm{r}=0.79)^{* *}$ & $(\mathrm{r}=0.50)^{*}$ \\
\multirow{2}{*}{$\begin{array}{l}\text { Relationship with body } \\
\text { weight }\end{array}$} & $3.38 \mathrm{~W}+371.8$ & $5.57 \mathrm{~W}+138.2$ & $8.28 \mathrm{~W}+669.4$ \\
& $(\mathrm{r}=0.78)^{* *}$ & $(\mathrm{r}=0.82)^{* *}$ & $(\mathrm{r}=0.62)^{* *}$ \\
\hline
\end{tabular}

Table 3. The overall mean female to male sex ratio of the three cichlid species from the commercial gill net fishery of the Victoria reservoir.

\begin{tabular}{ll}
\hline Species & $\begin{array}{l}\text { Female to male } \\
\text { ratio }\end{array}$ \\
\hline O. mossambicus & $1: 0.78$ \\
O. niloticus & $1: 1.44$ \\
T. rendalli & $1: 1.08$ \\
\hline
\end{tabular}

Gonad development and spawning: Percentages of the various maturity stages of females (excluding stage IV) in different months during 1990 for the three cichlid species are illustrated in Figure 2. Stage I represents immature individuals who could not be differentiated sexually. 


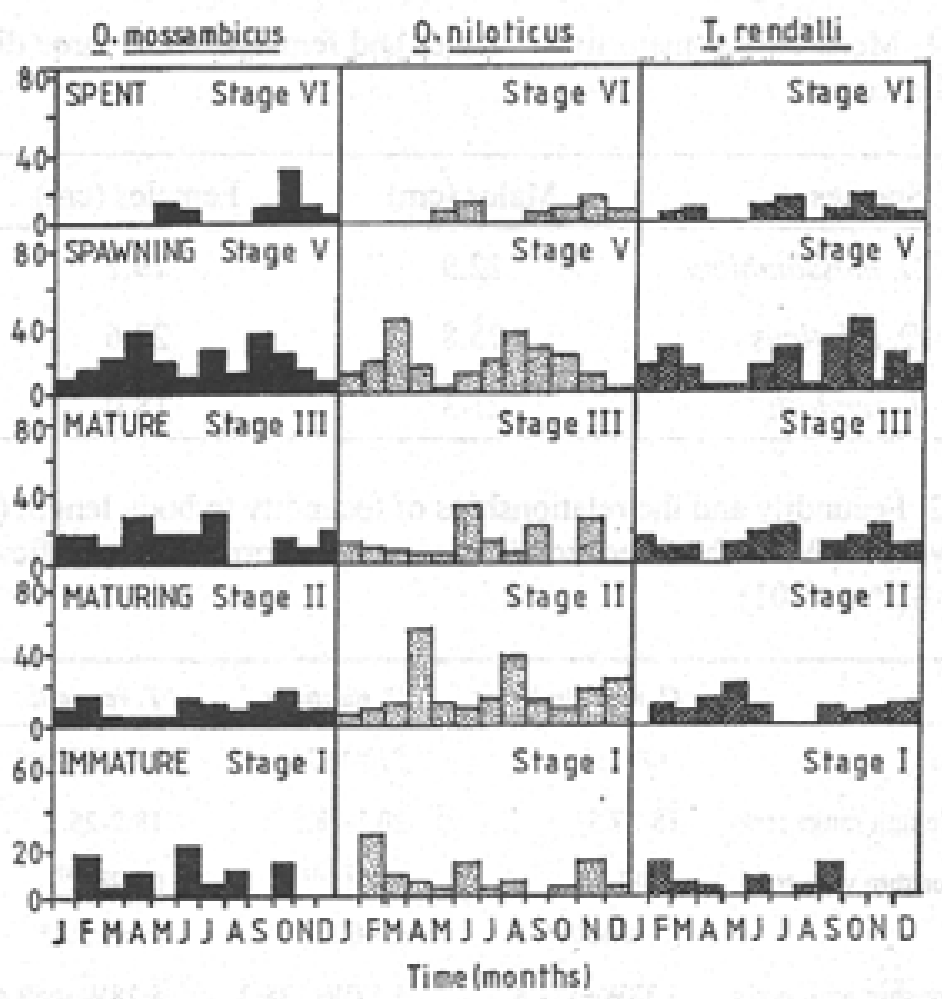

Figure 2. Monthly percentages of different maturity stages of females of the three cichlid species.

Females in spawning condition are present in all months, indicating that breeding occurs throughout the year with around three major peaks in all three species. Spearman's rank correlation coefficients (Neave \& Worthington 1992) between the gonadosomatic index and rainfall (Table 4) indicated that gonad maturation patterns of all three cichlid species studied were significantly correlated with the monthly rainfall pattern.

Table 4. Spearman's rank correlation coefficients $\left(\mathrm{r}_{\mathrm{n}}\right)$ between the monthly mean gonadosomatic index of the three cichlid species studied and monthly rainfall $\left({ }^{*} \mathrm{p}=0.05\right)$.

\begin{tabular}{lc}
\hline \multicolumn{1}{c}{ Species } & $\left(\mathrm{r}_{\mathrm{s}}\right)$ \\
\hline O. mossambicus & $0.5105^{*}$ \\
O. niloticus & $0.5470^{*}$ \\
T. rendalli & $0.2955^{*}$ \\
\hline
\end{tabular}




\section{Reproductive biology of cichlids}

\section{Discussion}

During the past, cichlids have been the focus of much experimental work in Sri Lanka since the lucrative cichlid fishery of this country has provided nutrition and income to many (Costa \& Abayasiri 1978; De Silva \& Chandrasoma 1980, Chandrasoma \& De Silva 1981, Amarasinghe \& Upasena 1985; Amarasinghe 1988; De Silva \& Sirisena 1988; De Silva \& De Silva 1991). But as yet, there is very little published information on comparative studies on reproductive of different cichlid species that have colonized Sri Lankan reservoirs.

Spawning cycles of fish are found to be correlated with environmental conditions. In Sri Lanka, the temperature and photoperiod are uniformly high throughout the year with minor seasonal variations. However, the rainfall pattern, which is more significantly variable, imposes a certain degree of seasonality on the breeding activities of most fish species. Breeding activities of all three cichlid species appear to peak during the rainy season when inflow of water and inundation of new areas in the littoral zone provide suitable conditions for the growth of young. Recent trends in the Victoria reservoir show a decrease in $O$. mossambicus in the catches with a corresponding increase in $O$. niloticus. $O$. niloticus appears to be more selective in its breeding habits, preferring areas close to inflows (Nathanael \& Silva 1996b). Among the three species, O. niloticus grows to the largest size, matures at a comparatively larger size and has the best correlation between fecundity and body size with a higher $\%$ of males in the population compared to other two cichlid species. These characteristics may have enabled this species to establish itself successfully in the reservoir.

The exponent of the fecundity length relationship is known to approximate 3 for fishes in general (Baegenal 1978). It is stated that variability of the exponent may be an indication of the adjustment of fecundity of a population to environmental conditions and an indication of the degree of adaptability of the species (De Silva 1986). Of the three species $O$. niloticus shows the best exponential value (3.15), further indicating that conditions in the reservoir are suitable for its propagation. $O$. niloticus is also known to have a lower temperature tolerance than $O$. mossambicus (Balarin \& Hatton 1979), and hence may inhabit the deeper, cooler layers of the reservoir, thereby being less susceptible to gill nets.

O. mossambicus was the most successful colonizer of this reservoir, contributing for about 58.7 percent by weight to commercial catches in 1990 . It displays an ability to reproduce even at a very small size, especially during severe drought. The adaptability of $O$. mossambicus and its capability of showing mixed life-history strategies (both $\mathrm{r}$ and $\mathrm{k}$ selected strategies; Amarasinghe et al. 1989) together with its ability to withstand environmental stress could partly account for its initial success in this reservoir. O. mossambicus also has the highest female to male sex ratio 
indicating that it has the advantage of multiplying rapidly, since females are the critical sex for egg laying. On the other hand, the progressive decline of $O$. mossambicus in the commercial catches since 1990 may be due to its inhabiting the warmer upper layers of the water making females more susceptible to small meshed gillnets. Selecting a correct mesh size and understanding the reproductive biology and behaviour of these fish species are therefore important for effective management of the fishery of the Victoria reservoir.

Results obtained by De Silva (1986) revealed that $O$. mossambicus grows to a larger size and has a higher fecundity ( 318 to 3,169 in fish ranging in total length between 16.5 to $32.0 \mathrm{~cm}$ ) in shallow dry zone reservoirs in Sri Lanka than those in the Victoria reservoir. The mean size at maturity was less for females (De Silva \& Chandrasoma 1980) and higher for males in Parakrama Samudra when compared with those in the Victoria reservoir. In Parakrama Samudra, females outnumbered the males with a female to male sex ratio of approximately $2: 1$. Thus, it appears that conditions in shallow dry zone reservoirs are more favourable for the propagation of $O$. mossambicus than deep reservoirs such as the Victoria.

Of the three cichlid species studied, $T$. rendalli shows the lowest colonization success in this reservoir. However, certain features such as having the highest fecundity, breeding mainly during the rainy season when conditions are favourable for survival of young, and early maturation ensures their survival in this reservoir. In Parakrama Samudra too, $T$. rendalli is a poor colonizer and the sex ratio, fecundity and mean size at maturity are similar to those obtained during the present investigation (Chandrasoma \& De Silva 1981).

Reproductive cycles of the three cichlid species inhabiting the Victoria reservoir are highly integrated and synchronized with seasonal rainfall. Differences in reproductive characteristics such as fecundity and egg size, mean size at maturity, sex ratio, and breeding habits clearly affect colonization success of the three cichlid species in this reservoir.

\section{Acknowledgments}

Financial assistance from NARESA (Grant NO: RG/92/B/10) is acknowledged. Our grateful thanks are also due to Mr. Tissa Alagoda (Department of Zoology, University of Peradeniya) for assistance with the illustrations. 


\section{Reproductive biology of cichlids}

\section{References}

Amarasinghe, U.S. 1988.

Empirical determination of a desirable mesh size for the gill net fishery of Oreochromis mossambicus (Peters) in a man-made lake in Sri Lanka. Asian Fisheries Science 2: 59-69.

Amarasinghe, U.S. \& S.S. De Silva, 1996.

Impact of Oreochromis mossambicus $X$ O. niloticus (Pisces: Cichlidae) hybridization on population reproductive potential and long-term influence on a reservoir fishery. Fisheries Management and Ecology 3: 239-249.

Amarasinghe, U.S. \& T. Upasena 1985.

Morphometry of a man-made lake in Sri Lanka: a factor influencing recruitment to cichlid fishery. Joumal of the National Aquatic Resources Agency, Sri Lanka 32: 121-129.

Amarasinghe, U.S., S.S. De Silva \& J. Moreau, 1989.

Spatial changes in growth and mortality and effects on the fishery of Oreochromis mossambicus (Pisces, Cichlidae) in a man-made lake in Sri Lanka. Asian Fisheries Science 3: 57-68.

Baegenal, T.B. 1978. Aspects of fish fecundity. In: Ecology of Freshwater Fish Production pp75-101. Blackwell Scientific Publications, Oxford. 365 p.

Balarin, J.D. \& J.P. Hatton 1979.

Tilapia; A guide to their biology and culture in Africa. University of Sterling, Sterling. $174 \mathrm{pp}$.

Chandrasoma, J. 1980.

Aspects of the reproductive biology of Tilapia melanopleura and Puntius sarana, an exotic and an indigenous species respectively, in an ancient man-made lake in Sri Lanka. M.Phil thesis. University of Kelaniya, Kelaniya. Sri Lanka.

Chandrasoma, J. \& S.S. De Silva 1981.

Reproductive biology of Puntius sarana, an indigenous species and Tilapia rendalli an exotic, in an ancient man-made lake in Sri Lanka. Fisheries Management 12 (1): 17-28.

Costa, H.H. \& R. Abeyasiri 1978.

The hydrobiology of Colombo (Beire) lake. VII. The food and feeding ecology of the fish, Tilapia mossambica. Spolia Zeylanica 32: 93-110.

De Silva, K.H.G.M. \& P.K. De Silva 1991.

The role of Tilapia species (Family Cichlidae) in the fishery of three upland deep reservoirs of Sri Lanka. Vidyodaya Joumal of Science 3: 91-98. 
De Silva, S.S. 1986.

Reproductive biology of Oreochromis mossambicus populations of man-made lakes in Sri Lanka: a comparative study. Aquaculture and Fisheries Management 17: 31-47.

De Silva, S.S. \& J. Chandrasoma 1980.

Reproductive biology of Sarotherodon mossambicus an introduced species in an ancient man-made lake in Sri Lanka. Environmental Biology of Fishes 5 (3): 253-259.

De Silva, S.S. \& H.K. Sirisena 1988.

Observations on the nesting habits of Oreochromis mossambicus (Peters) (Pisces: Cichlidae) in Sri Lankan reservoirs. Joumal of Fish Biology 33: 689-696.

Lowe-McConnell, R.H. 1982.

Tilapias in fish communities. In: The Biology and Culture of Tilapias. (R.S.V. Pullin \& R.H.Lowe-McConnell eds.). pp. 83-113. Intemational Centre for living Aquatic Resources Management, Manila, Philippines.

Nathanael, S. \& E.I.L. Silva 1996 a

Food and nest site availability: An indicator of the colonization of a highland reservoir in Sri Lanka by three species of cichlids. Sri Lanka Journal of Aquatic Sciences 1: 81-90

Nathanael, S. \& E.I.L. Silva 1996 b

Distribution of exotic cichlids in the Victoria reservoir, Sri Lanka.

Sri Lanka Journal of Aquatic Sciences 1: 91-101 


\title{
The Role of Non-cichlid Exotics in the Fishery of the Victoria Reservoir, a Deep Upland Reservoir in Sri Lanka
}

\author{
S. NATHANAEL and E.I.L.SILVA* \\ Institute of Fundamental Studies, Hantana Road, Kandy, Sri Lanka. \\ *Corresponding author (E-mail: sil@kln.ac.lk)
}

\begin{abstract}
At present, the non-cichlid exotics appear to be not significant in the reservoir fishery of Sri Lanka. They are nonetheless an exploitable resource for the future as a source of protein for the rural poor. Catch statistics of the gillnet fishery in the Victoria reservoir maintained for an 18-month period indicate that of the five species of non-cichlid exotics stocked in the reservoir only two species, namely, the common carp (Cyprinus carpio) and Rohu (Labeo rohita), had an impact on the commercial fishery. Although stocking the reservoir ceased since July 1990 , there has been a marked increase in the number of common carp in commercial catches towards the latter part of this investigation. Unlike the common carp, only large-sized Rohu are being netted, indicating the possibility of natural breeding of common carp within or in the vicinity of the reservoir.
\end{abstract}

\section{Introduction}

Reservoirs have played an important role in the development of ancient agro-civilizations of Sri Lanka. Since Sri Lanka has no natural lakes, inland fish production has for a long time been from shallow irrigation reservoirs in the dry zone. As the accent was on marine fisheries, the potential of inland waters as a biological resource was rather unidentified until the second half of the twentieth century.

Since the native fishes of Sri Lanka are truly riverine or marsh-dwelling, they constitute only a very small proportion of the reservoir fishery. In order, therefore, to sustain a fishery, reservoirs were stocked under government patronage with two groups of piscine exotics, namely the cichlids and the non-cichlids.

Among the cichlids, the pandemic Oreochromis mossambicus is a proven success, on which the entire inland fishery of Sri Lanka has become established. Comparatively little information is available however, on the 
contribution of non-cichlid exotics to the reservoir fishery of Sri Lanka. Among non-cichlid exotics, the common carp is a popular food fish and has the potential of providing a stable source of high quality fish seed needed for fish culture.

The Mahaweli River has been held back by a double curvature, concrete dam at the Victoria Falls, $3 \mathrm{~km}$ downstream of the confluence of the Mahaweli and the Hulu rivers, giving rise to the Victoria reservoir $\left(7^{\circ} 15^{\prime}-7^{\circ} 19^{\prime} \mathrm{N}\right.$ and $\left.80^{\circ} 39^{\prime}-80^{\circ} 48^{\prime} \mathrm{E}\right)$. The Victoria reservoir was commissioned in 1985, inundating some large cocoa and coffee estates with rich soils. The reservoir, with its steep banks and irregular shoreline, is characterized by a typical intermediate lotic-lentic type of ecosystem. Some hydrological and morphometric characteristics of the Victoria reservoir are given in Table 1.

Table 1. Some hydrological and morphometric characteristics of the Victoria reservoir.

\begin{tabular}{lc}
\hline Maximum Flood Level $(\mathrm{m})$ & 441.2 \\
Lowest draw down level $(\mathrm{m})$ & 370.0 \\
Annual draw down $(\mathrm{m})$ & $28-71.2$ \\
Gross storage capacity (million $\left.\mathrm{m}^{3}\right)$ & 722.0 \\
Catchment $\left(\mathrm{km}^{2}\right)$ & 1,891 \\
Area (ha) & 2,270 \\
Maximum depth $(\mathrm{m})$ & 102 \\
Mean depth $(\mathrm{m})$ & 32.2 \\
Shoreline $(\mathrm{km})$ & 115 \\
Shoreline development & 6.66 \\
\hline
\end{tabular}

Following inundation, the Victoria reservoir has been colonized by several indigenous riverine fish species, which had no significant commercial impact. The Ministry of Fisheries therefore, stocked this reservoir with African cichlids and non-cichlid exotics (Indian, Chinese and common carps) with a view towards utilizing this water body to enhance fish yield.

Edirisinghe (1990) records the susceptibility of the common carp to gill nets in the Victoria reservoir while Silva (1991) and De Silva \& De Silva (1991) have estimated the percentage contribution of non-cichlids in the fishery of three Mahaweli reservoirs. However, no systematic studies 


\section{Non-cichlid exotics in Victoria resenvir}

have been conducted hitherto to determine the role of non-cichlid exotic fish in any of the Sri Lankan reservoirs. The present study was therefore carried out to investigate on the role of non-cichid exotics in the fishery of the Victoria reservoir in the Mahaweli river basin in Sri Lanka (Fig. 1).

\section{Materials and methods}

During the 18-month study period from March 1990 to September 1991, catch statistics were collected at least thrice a month from individual fishermen of the major fish landing sites around the reservoir.

The total weight of the catch and the number and the weight of non-cichlid exotics present in the catch were recorded on each sampling date. The total lengths of common carp and Rohu in the gillnet catches were measured to the nearest millimeter. On each sampling day, data was collected from $20-25 \%$ of the total fishing operations of the reservoir.

Data on water level fluctuation of the reservoir during the study period was obtained from the Headworks Division of the Mahaweli Authority.

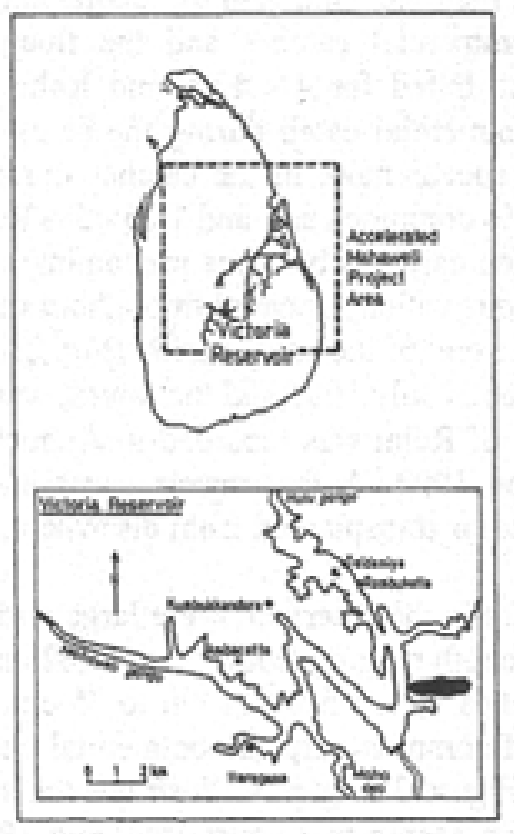

Figure 1. Accelerated Mahaweli Project area and Victoria reservoir with main fish landing sites. 


\section{S. Nathanael \& E.I.L. Silva}

\section{Results}

The major fishing gear operated in the reservoir was the gillnets. These were laid late in the evening and hauled in early morning of the following day. Nets were laid down to a depth of about $3-5 \mathrm{~m}$. There were 48 fiberglass boats and a few log crafts operated by about 66 fishermen in the reservoir during the study period. Until July 1990 , only the gillnets with a minimum mesh size of $9 \mathrm{~cm}$ stretched mesh were allowed to be used in the reservoir. However, after withdrawing the state patronage for inland fisheries in July 1990, gillnets with smaller mesh sizes were also used. Sporadic cast netting and hook and line fishing, too, were employed, but they did not contribute significantly to the overall catch.

The number of non-cichlid exotics stocked after sealing of the reservoir is given in Table 2. Although five species of non-cichlid exotics have been stocked in this reservoir, only two species, namely the common carp (Cyprinus carpio) and Rohu (Labeo rohita), have appeared consistently in commercial catches during the study period.

Figure 2 shows the temporal variation of the relative abundance of different types of fish, i.e., indigenous, exotic cichlids and non-cichlid exotics, in the commercial catches and the fluctuation in water level. Common carp contributed for $4-12 \%$ and Rohu for $0.08-0.70 \%$ (by number) of the commercial catch during the study period. Common carp and Rohu tend to appear more in the catches during the periods of high drawdown ( 24 - $35 \%$ common carp, and 1.25 - $5 \%$ Rohu by weight).

The common carp has been the predominant non-cichlid species in the Victoria reservoir, which appeared throughout the study period with an increase towards the end of the study period (Fig. 2), the highest percentage of common carp was in July 1991 and the lowest was in October 1990. The highest percentage of Rohu was recorded in August 1991, and the lowest was in May - June 1990. A few mirror carps and red carps, probably accidentally stocked or transplanted from elsewhere, appeared sporadically in some landings.

Rohu caught in the reservoir, were large with an average weight of $3.0 \mathrm{~kg}$ and a total length ranging from $35 \mathrm{~cm}$ to $62 \mathrm{~cm}$. The size of common carp in gillnet catches varied from $11 \mathrm{~cm}$ to $75 \mathrm{~cm}$. Monthly variations in the mean length of common carp in commercial catches during the study period is given in Figure 3. Figure 4 illustrates the size-classes of common carp caught between March to August 1990 and 1991. Figure 4 indicates that the common carp in this reservoir could grow to a large size while individuals of small sizes too are caught. 


\section{Non-cichlid exotics in Victoria reservoir}

Table 2. The number of fingerlings of non-cichlid exotics stocked in the Victoria reservoir after sealing in 1984 (Source: Ministry of Fisheries and Ocean Resources).

\begin{tabular}{llcc}
\hline Species & Common name & $\begin{array}{c}\text { Country } \\
\text { of origin }\end{array}$ & $\begin{array}{r}\text { Number } \\
\text { stocked }\end{array}$ \\
\hline Cyprimus carpio & Common carp & Europe & 151,500 \\
Aristichthys nobilis & Big head carp & China & 39,975 \\
$\begin{array}{l}\text { Ctenopharyngodon } \\
\text { idella }\end{array}$ & Grass carp & China & 6,500 \\
Cirrhinus mrigala & Mrigal & India & 22,500 \\
Labeo rohita & Rohu & India & 140,510 \\
\hline
\end{tabular}

\section{Discussion}

Preliminary observations revealed that except for the common carp (Cyprinus carpio), non-cichlid exotics do not appear to play a significant role in the commercial fishery of the Victoria reservoir. Although Rohu appeared in gillnet catches of the commercial fishery during the study period, the fate of this species is doubtful, especially since there is no evidence of its breeding naturally in the reservoir.

Common carp is very popular as a food fish among people living in the vicinity of the Victoria reservoir. These fish grow to a larger size than exotic cichlids, which at present are the mainstay of the commercial fishery. Although the stocking densities of common carp and Rohu are almost the same, the contribution of common carp to the fishery is much higher than that of Rohu. Moreover, unlike Rohu, a wide size range of common carps (including small sized fish) are netted.

Besides, although stocking this reservoir with non-cichlid exotics ceased completely after July 1990 as a consequence of changing of the government policy on inland fisheries, there has been a steady increase in the proportion of common carp in gillnet catches. Furthermore, collection of common carp fingerlings in rivulets leading to the Hulu River by the first author strengthens the view that common carp breed naturally in the Victoria reservoir, or in the upstream of inflows such as the Hulu River and Maha Oya.

Records on natural breeding of common carp in Sri Lankan reservoirs are scarce. De Silva (1983) reports that there is increasing evidence for natural breeding of common carp in certain reservoirs since males in running condition have been observed on many occasions. This 


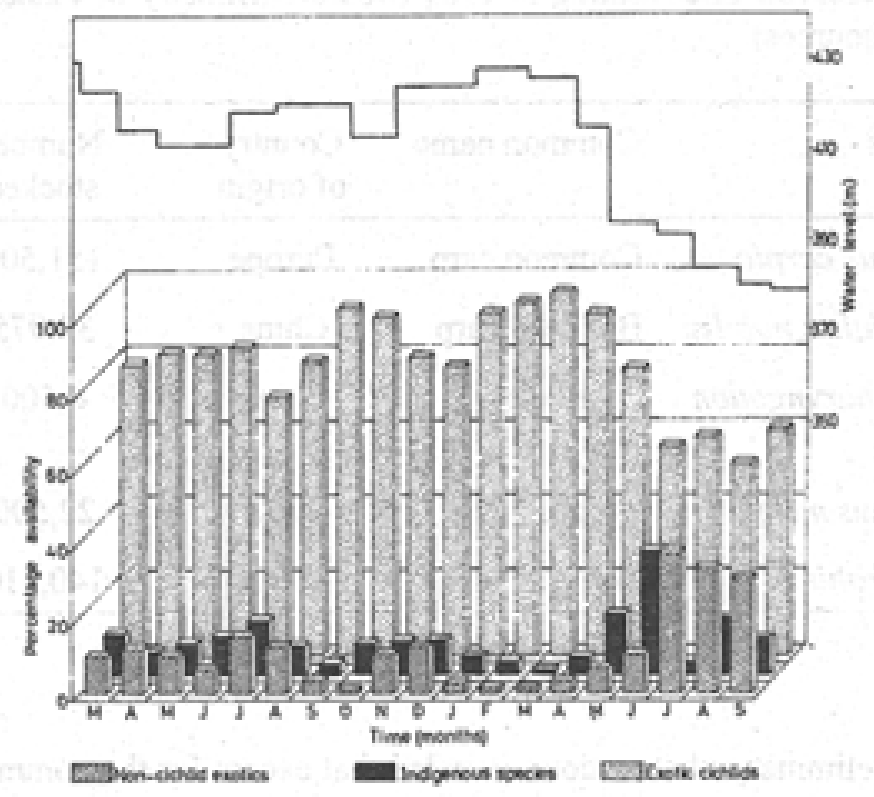

Figure 2. Temporal variation in the relative abundance of non-cichlid exotics, exotic cichlids and indigenous fish in the commercial catches and the fluctuation of water level in the Victoria reservoir during the study period.

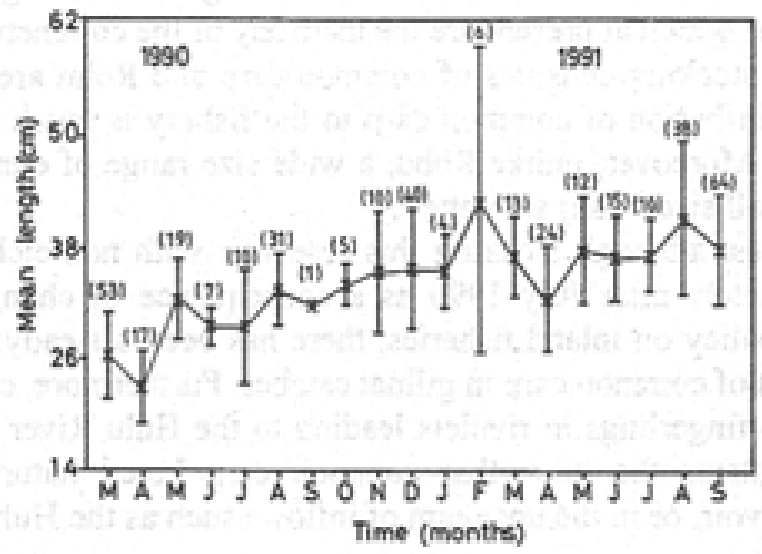

Figure 3. Mean length of common carp in the commercial catches during the study period. The number of fish measured is given within brackets. Vertical bars indicate standard deviation. 


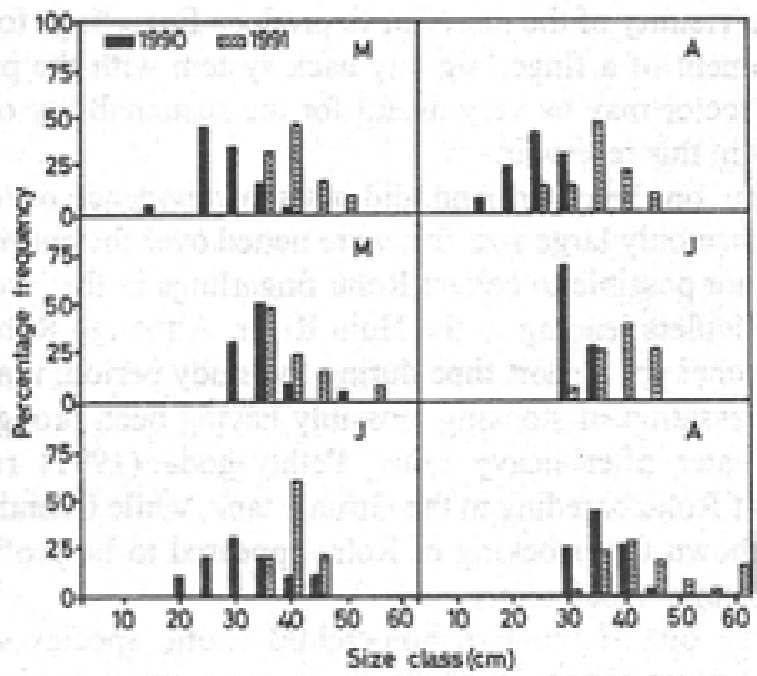

Figure 4. The size-classes of common carp caught from March to August in 1990 and 1991

observation holds true for the Victoria reservoir as well, since on several occasions females in spawning condition and sexually mature males were collected from a fish market in close proximity to the reservoir. Sreenivasan \& Thayaparan (1983) stated that common carp may be breeding in Ulhiti Oya and the Maduru Oya reservoirs. Hettiarachchi (1983) suggests that villus in the downstream of the Mahaweli River could provide ideal habitats for culturing carp fingerlings.

Unlike exotic cichlids, common carp does not nest or provides parental care. This may result in low survival of young especially in shallow lowland reservoirs where avian and piscine predation is high (Schiemer \& Duncan, 1983). It is possible that the success of common carp in the Victoria reservoir could be due to low predator pressure. It is also likely, that a large proportion of these bottom dwellers escape being trapped in gillnets laid in surface waters of the reservoir as suggested by De Silva (1992). Further, the presence of tree stumps at the bottom precludes the use of any type of bottom gear in the reservoir, thereby increasing the survival of this species.

Results obtained during this preliminary investigation highlight the necessity of long term monitoring of the fishery at the Victoria reservoir to obtain detailed information on the status of common carp in the commercial fishery. In the face of heavy illegal fishing, following the withdrawal of state patronage and supervisory control, it appears that natural recruitment alone would not be sufficient to sustain the common carp fishery in this reservoir. Therefore, introducing aquaculture practices to the community 
living in the vicinity of the reservoir to produce fingerlings for stocking and the development of a fingerling buy back system with the participation of the private sector may be very useful for the sustainability of the common carp fishery in this reservoir.

Rohu, on the other hand, did not show evidence of breeding in the reservoir, since only large size fish were netted over the entire study period. It was also not possible to collect Rohu fingerlings in the littoral zone or in any of the rivulets leading to the Hulu River. Although Rohu disappeared from the catches for a short time during the study period, it appeared again even after cessation of stocking, possibly having been brought in with the inflowing water after heavy rains. Pethiyagoda (1991) reports on the possibility of Rohu breeding in the Giritale tank, while Chandrasoma (1992, 1996) has shown that stocking of Rohu appeared to be profitable in some lowland perennial reservoirs.

Three out of the five non-cichlid exotic species stocked in the Victoria reservoir appear only rarely in commercial landings. All these species are riverine fish and are therefore incapable of breeding in the reservoir. Decades of government attempts to stock these species in order to increase fish production appears to be an unmitigated failure in both upland and lowland reservoirs of Sri Lanka, since the recovery rates are very low, frequent stocking with fingerlings is expensive, and no sustained fishery has hitherto been established. It is therefore necessary to abandon such ad hoc stocking strategies, and concentrate on developing more effective methods to develop the inland fishery of Sri Lanka.

The results of this study show that of the non-cichlid exotics, the common carp appears to a very promising resource for future propagation in the Victoria reservoir. More detailed studies are therefore necessary to develop and exploit the full potential of this resource in the future.

\section{Acknowledgements}

We are grateful to late Professor Cyril Ponnamperuma and Professor C.B. Dissanayake, former Directors, for their kind encouragement and provision of facilities to carry out this research at the Institute of Fundamental Studies. The International Foundation for Science, Sweden, provided financial assistance for this work under the grant agreement $\mathrm{Np}$ : 4/1526-1. We also wish to thank Mr. Upul Lokumeegoda for assistance in the field and Mr. Tissa Alagoda (Department of Zoology, University of Peradeniya) for the kind assistance rendered in the preparation of illustrations. 
Non-cichlid exotics in Victoria resenoir

\section{References}

Chandrasoma, J. 1992.

Performance of Rohu, Labeo rohita (Ham.), in some perennial and seasonal reservoirs in Sri Lanka - an evaluation. Journal of Applied Ichthyology 8: 228-233.

Chandrasoma, J. 1996.

Impact of stocking of exotic carp species on the fish production of man-made lakes in Sri Lanka-A reappraisal. Sri Lanka Journal of Aquatic Sciences 1: 71-80.

De Silva, K.H.G.M. 1992.

Limnology and fishery of three recently impounded reservoirs in Sri Lanka. In: Reservoir Fisheries of Asia (S.S. De Silva ed.), pp. 12-22, Proceedings of the $2^{\text {ad }}$ Asian Reservoir Fisheries workshop held in Hangzhou, China.

De Silva, K.H.G.M. \& P.K. De Silva 1991.

The role of Tilapia species (Family Cichlidae) in the fishery of three upland deep reservoirs of Sri Lanka. Vidyodaya Journal of Science 3: (1) $91-98$

De Silva, S.S. 1983.

The reservoir fishery: present status and future strategies. Journal of Inland Fisheries 2: $3-13$.

Edirisinghe, U., N. Sirisena \& R.M.S. Bandara 1990.

Catchability of common carp by gillnetting. Proceedings of the 46 th

Annual Sessions of the Sri Lanka Association for the Advancement of Science, (Abstract). 51 p.

Hettiarachehi, A. (1983)

Fisheries of villus in the Mahaweli river system of Sri Lanka. Journal of Inland Fisheries 2: 50 -56

Pethiyagoda, R. 1991.

Freshwater fishes of Sri Lanka. The Wildlife Heritage Trust of Sri

Lanka. 362 p.

Schiemer, F. \& A. Duncan 1983.

Parakrama Samudra Project-a summary of main results. In: Limnology of Parakrama Samudra, Sri Lanka: a case study of ancient man-made lakes in the tropics (F. Schiemer ed.), pp. 201206, Developments in Hydrobiology 12, The Hague.

Silva, E.I.L. 1991.

Limnology and fish yields of newly built standing water bodies in the Mahaweli River Basin, Sri Lanka. Internationale Vereinigung für Theoritische and Angewandte Limnologie 24: 1425 - 1429.

Sreenivasan, A. \& K. Thayaparan 1983.

Fisheries development in the Mahaweli reservoir systems. Journal of Inland Fisheries 2: 34 - 49. 